\title{
Bandwidth and Gain Enhancement of Patch Antenna with Stacked Parasitic Strips Based on LTCC Technology
}

\author{
Li Li, Yong Zhang, Jinhong Wang, Wei Zhao, Shuang Liu, and Ruimin Xu \\ EHF Key Laboratory of Fundamental Science, University of Electronic Science and Technology of China, Chengdu 611731, China \\ Correspondence should be addressed to Li Li; uestclee228@hotmail.com
}

Received 17 March 2014; Accepted 19 June 2014; Published 3 July 2014

Academic Editor: P. Mohanan

Copyright (C) $2014 \mathrm{Li} \mathrm{Li} \mathrm{et} \mathrm{al.} \mathrm{This} \mathrm{is} \mathrm{an} \mathrm{open} \mathrm{access} \mathrm{article} \mathrm{distributed} \mathrm{under} \mathrm{the} \mathrm{Creative} \mathrm{Commons} \mathrm{Attribution} \mathrm{License,} \mathrm{which}$ permits unrestricted use, distribution, and reproduction in any medium, provided the original work is properly cited.

\begin{abstract}
A compact patch antenna with stacked parasitic strips (SPSs) based on low temperature cofired ceramic (LTCC) technology is presented. By adding three pairs of SPSs above the traditional patch antenna, multiple resonant modes are excited to broaden the bandwidth. At the same time, the SPSs act as directors to guide the antenna radiation toward broadside direction to enhance the gain. The measured results show that the prototype antenna achieves an impedance bandwidth of $16 \%$ for $S_{11}<-10 \mathrm{~dB}$ (32.1$37.9 \mathrm{GHz}$ ) and a maximum gain of about $8 \mathrm{dBi}$ at $35 \mathrm{GHz}$. Furthermore, the radiation patterns and gain are relatively stable within the operating bandwidth. The total volume of the antenna is only $8 \times 8 \times 1.1 \mathrm{~mm}^{3}$.
\end{abstract}

\section{Introduction}

The interest in millimeter-wave radars and high data-rate wireless communications systems has grown explosively, which has led to increasing requirements for compact, high performance, and low cost antennas. In recent years, low temperature cofired ceramic (LTCC) technology has emerged as an attractive solution for these requirements due to its high level of compactness and mature multilayer fabrication capability [1-3]. However, the widely used microstrip antennas suffer from narrow bandwidth and low gain, especially when fabricated on LTCC substrate due to the high dielectric constant of LTCC material. To solve these problems, a number of techniques have been developed.

The common methods to broaden the bandwidth include the use of thick substrates, embedded air cavities [4], different shape patches and probes [5, 6], and cutting of slots [7]. Also stacked patches are often implemented in LTCC antenna design to achieve wide bandwidth [8]. To enhance the gain, there have been quite a few methods reported. The most popular method is to reduce the surface waves by constructing electromagnetic bandgap (EBG) structure [9]. The use of air cavity to lower the effective dielectric constant has been reported in [10]. Another considered method is to direct the antenna radiation with parasitic elements [11]. However, it is an ongoing challenge to design compact patch antennas with both wide bandwidth and high gain.

This paper presents a compact LTCC patch antenna that employs stacked parasitic strips (SPSs). This simple and practical configuration not only can produce a wide bandwidth by introducing adjacent resonances but also can yield a high gain due to its director effect. A prototype antenna at Ka-band was manufactured and measured to verify the effectiveness of the design concept. The results are presented and compared with those of a single-patch antenna.

\section{Antenna Design}

The LTCC substrate used in this research is Ferro A6-M which has good high frequency performance $\left(\varepsilon_{r}=5.7\right.$, $\tan \delta=0.003$ ). The thickness of each layer is $0.094 \mathrm{~mm}$ after sintering and all buried, exposed, and filled conductors are made of silver. Figure 1(a) shows the expanded view of the proposed antenna. The antenna is designed in an 11-layer LTCC substrate and includes two parts: an aperture-coupled patch antenna and three pairs of SPSs. For the sake of brevity, only parts of via holes are shown in the figure. The details for each metal layer are shown in Figure 1(b). 


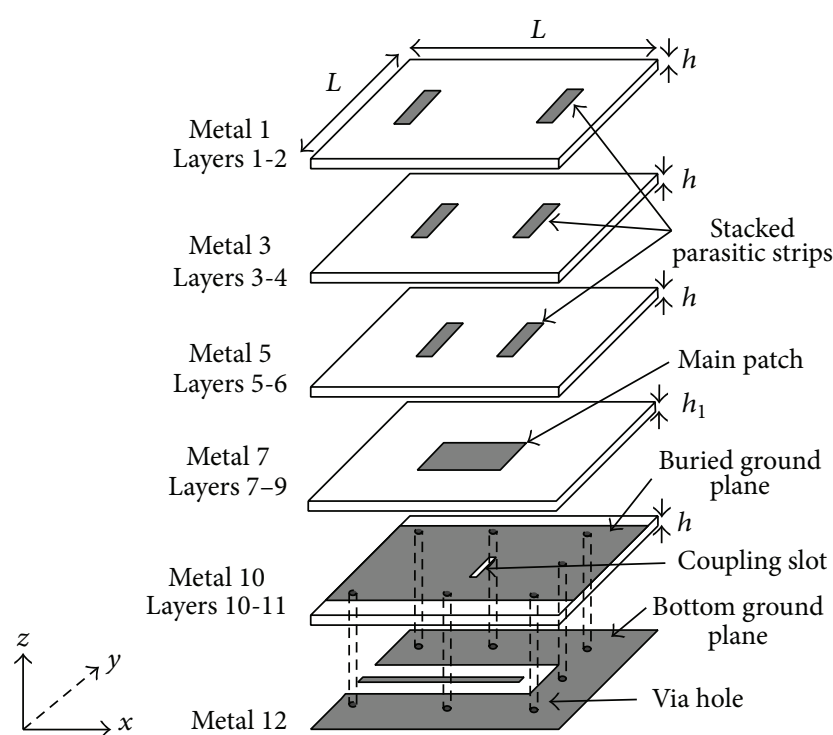

(a)

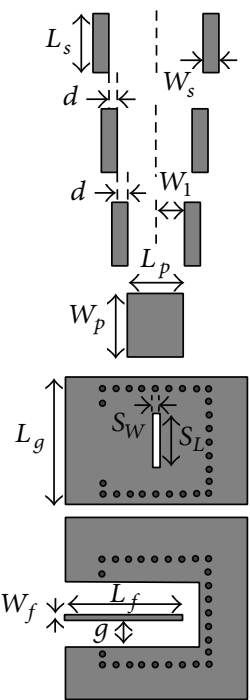

(b)

FIGURE 1: Configuration of the proposed antenna. (a) Expanded view. (b) Metal layer details.

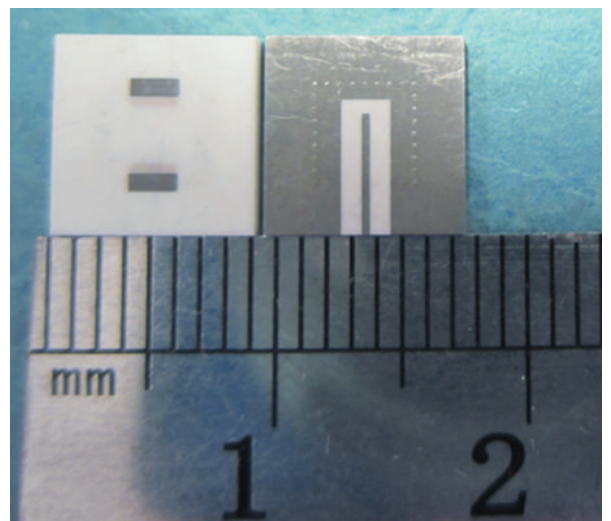

(a)

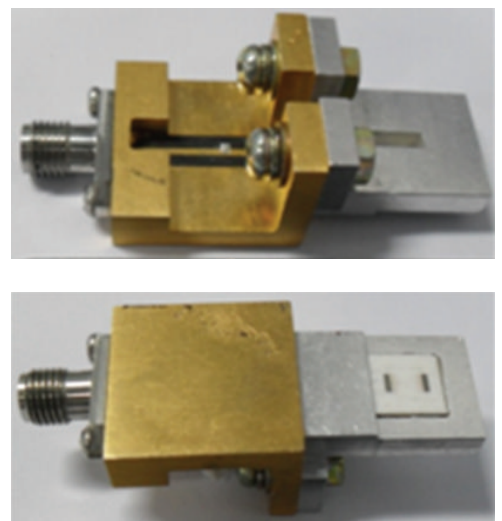

(b)

FIgURE 2: Top view and bottom view of the antenna and the fixture. (a) The fabricated antenna. (b) The fixture for measurement.

The aperture-coupled patch antenna is the fundamental part of the proposed antenna. The center frequency of the proposed antenna $f_{0}$ is chosen at $35 \mathrm{GHz}$, and then the initial dimensions of the main patch $\left(L_{p} \times W_{p}\right)$ can be approximately calculated with the well-known formulas as follows [12]:

$$
\begin{aligned}
L_{p} & =\frac{c}{2 f_{0} \sqrt{\varepsilon_{r e}}}-2 \Delta L, \\
W_{p} & =\frac{c}{2 f_{0}}\left(\frac{\varepsilon_{r}+1}{2}\right)^{-1 / 2},
\end{aligned}
$$

where $\varepsilon_{r e}$ is the effective dielectric constant and $\Delta L$ is an empirical correction factor; formulas for them can be easily found in the literatures. Strictly speaking, equations in (1) are more suitable for the traditional microstrip antenna, but those equations still can be used to get initial values here.
The aperture-coupled structure is employed to feed the antenna due to its advantages of eliminating spurious radiation from the feed line and reducing the backward radiation [13]. It is easy to match the antenna to $50 \Omega$ by controlling the dimensions of the coupling aperture $\left(L_{s}\right.$ and $\left.W_{s}\right)$ and the microstrip feed line $\left(W_{f}\right.$ and $\left.L_{f}\right)$. The feed line is mounted on the same metal layer with the U-shaped backside ground plane and can be regarded as a microstrip line, because it is separated by a large gap $L_{g}$ from the edge of backside ground plane. Thus, it is unnecessary to model it as grounded coplanar waveguide (GCPW). Compared with the stripline feeding structure widely used in LTCC substrate, this feeding structure is more convenient to feed the antenna during testing, because it can be connected to coaxial connector directly without using any transition, which will introduce additional loss of energy. Since a completely solid ground plane may cause camber problems, the buried ground plane is 


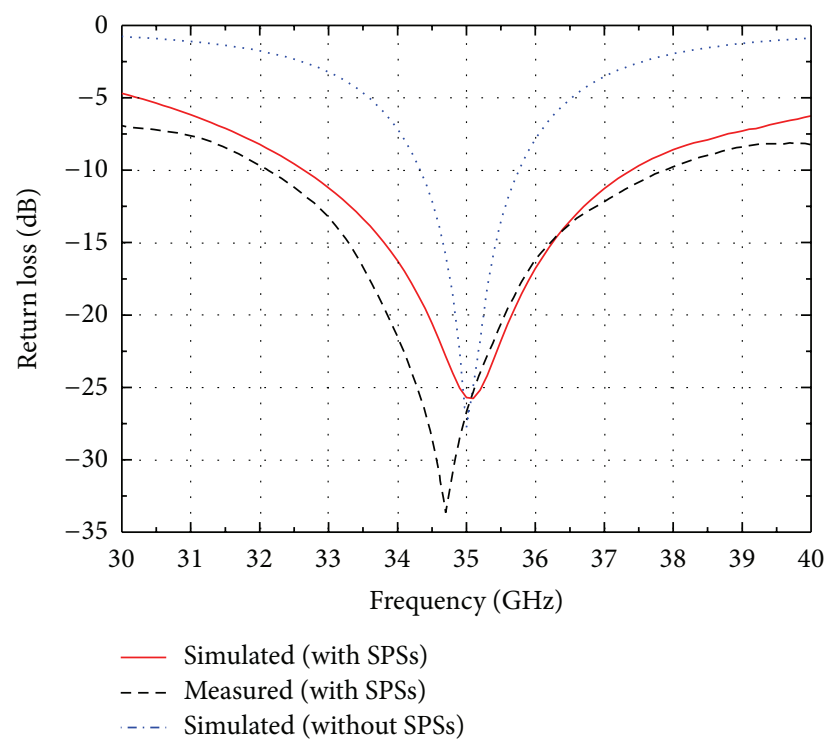

FIGURE 3: The simulated and measured return losses of the patch antennas with and without SPSs.

TABLE 1: The final optimized dimensions of the proposed antenna (unit: $\mathrm{mm}$ ).

\begin{tabular}{lccccccccccccccc}
\hline Parameter & $L_{s}$ & $W_{s}$ & $W_{1}$ & $L_{p}$ & $W_{p}$ & $S_{L}$ & $S_{W}$ & $L_{g}$ & $L_{f}$ & $W_{f}$ & $L$ & $d$ & $g$ & $h$ & $h_{1}$ \\
\hline Dimension & 1.9 & 0.7 & 0.75 & 1.5 & 1.9 & 1.7 & 0.3 & 5 & 4.6 & 0.26 & 8 & 0.4 & 1 & 0.188 & 0.282 \\
\hline
\end{tabular}

partially etched at its two sides, which has negligible effects on antenna performance. The two ground planes are connected by a fence of via holes to create a cavity effect for suppressing spurious parallel plate modes [14].

The unique feature of this antenna design is the SPSs which are placed parallel to the radiating edges of the main patch. All strips have the same dimensions $\left(L_{s} \times W_{s}\right)$, and they gradually flare with equal progressive space $d$ and height $h$. The strips act as directors to guide the antenna radiation toward broadside direction (i.e., the $+z$ direction); thus the gain is enhanced. Meanwhile, multiple resonant modes are excited by the SPSs and the main patch. The frequencies of the multiple resonant modes can be merged to exhibit a wide bandwidth by choosing proper dimensions. However, the widest bandwidth and the highest gain require different dimensions. Therefore, a trade-off has been made in this design to achieve acceptable bandwidth and gain. The final optimized dimensions of the proposed antenna are presented in Table 1 , and all the descriptions of the design parameters in Table 1 are labeled in Figure 1 accordingly.

\section{Simulated and Measured Results}

The performances of the LTCC patch antennas with (proposed antenna) and without SPSs (a single-patch antenna) were simulated by Ansoft HFSS. To validate the design concept, a prototype antenna was fabricated and tested. Also, a fixture used for antenna measurement was fabricated. The fixture is composed of a coaxial connector and a section of microstrip line. The feed line of the antenna and the microstrip line on the fixture are bonded by gold wire.
Photographs of the fabricated antenna and the fixture are shown in Figure 2. The simulated and measured return losses of the patch antennas with and without SPSs are compared in Figure 3. A good agreement is achieved between the simulated and the measured results of the proposed antenna. There is a frequency shift of $0.3 \mathrm{GHz}$, which is mainly caused by the variation of dielectric constant. The measured impedance bandwidth for $S_{11}<-10 \mathrm{~dB}$ of the proposed antenna is $16 \%$ (from 32.1 to $37.9 \mathrm{GHz}$ ), which is about four times wider than the simulated result of the single-patch antenna.

The radiation patterns and gain of the proposed antenna were measured in an anechoic chamber with NSI 2000 farfield measurement software. Figure 4 shows the simulated and measured radiation patterns in $E$-plane ( $x z$-plane) and $H$-plane ( $y z$-plane) at 33,35 , and $37 \mathrm{GHz}$, respectively. As can be seen, the measured results agree well with the simulated results. Also the radiation patterns are relatively stable throughout the operating bandwidth.

Figure 5 compares the simulated and measured gain of the patch antennas with and without SPSs. The proposed antenna achieves an average gain of $7.4 \mathrm{dBi}$ within its operating bandwidth and a maximum gain of about $8 \mathrm{dBi}$ at $35 \mathrm{GHz}$, which is about $2.8 \mathrm{~dB}$ higher than the simulated result of the single-patch antenna.

\section{Conclusion}

A novel compact patch antenna with SPSs based on LTCC technology has been developed. Experimental results show that the proposed antenna achieves wide bandwidth as well 




(a)

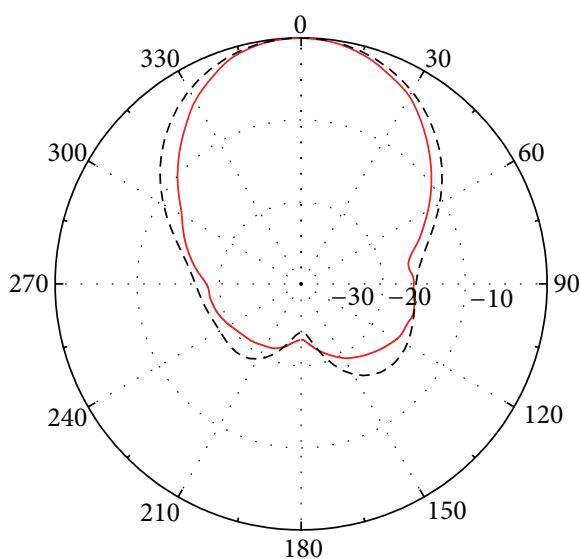

(c)

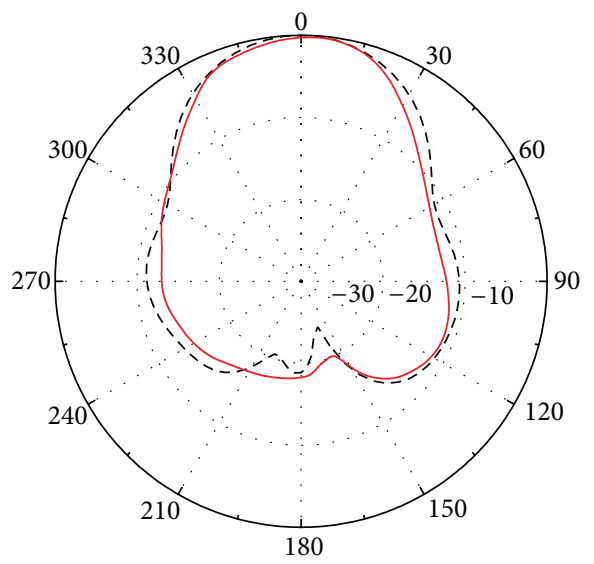

- Measured

- - Simulated

(e)

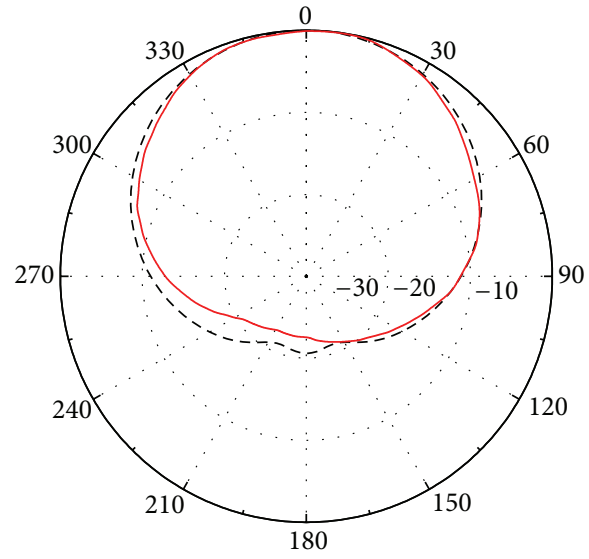

(b)

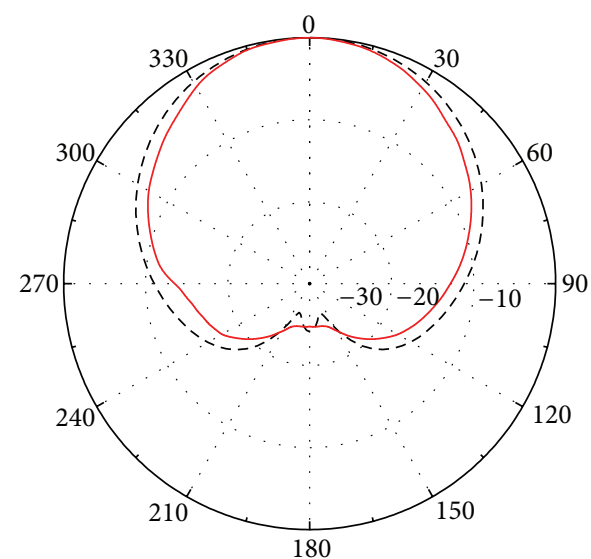

(d)

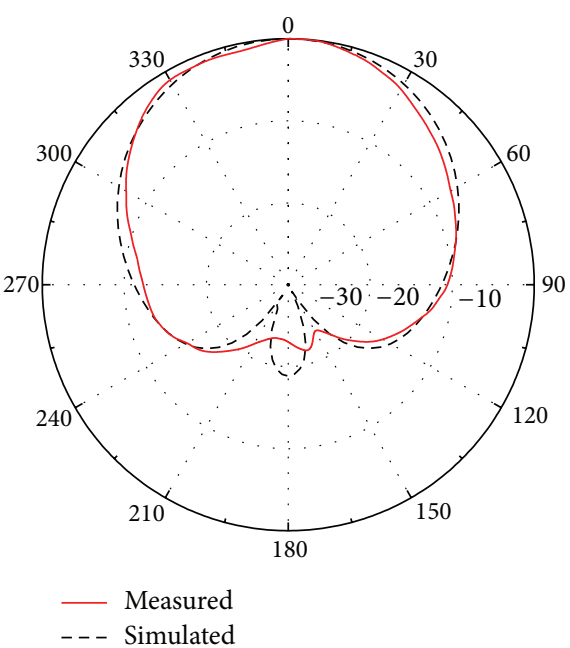

(f)

FiguRE 4: Simulated and measured radiation patterns of proposed antenna. (a) $33 \mathrm{GHz}, x z$-plane; (b) $33 \mathrm{GHz}, y z$-plane; (c) $35 \mathrm{GHz}, x z$-plane; (d) $35 \mathrm{GHz}, y z$-plane; (e) $37 \mathrm{GHz}, x z$-plane; and (f) $37 \mathrm{GHz}, y z$-plane. 


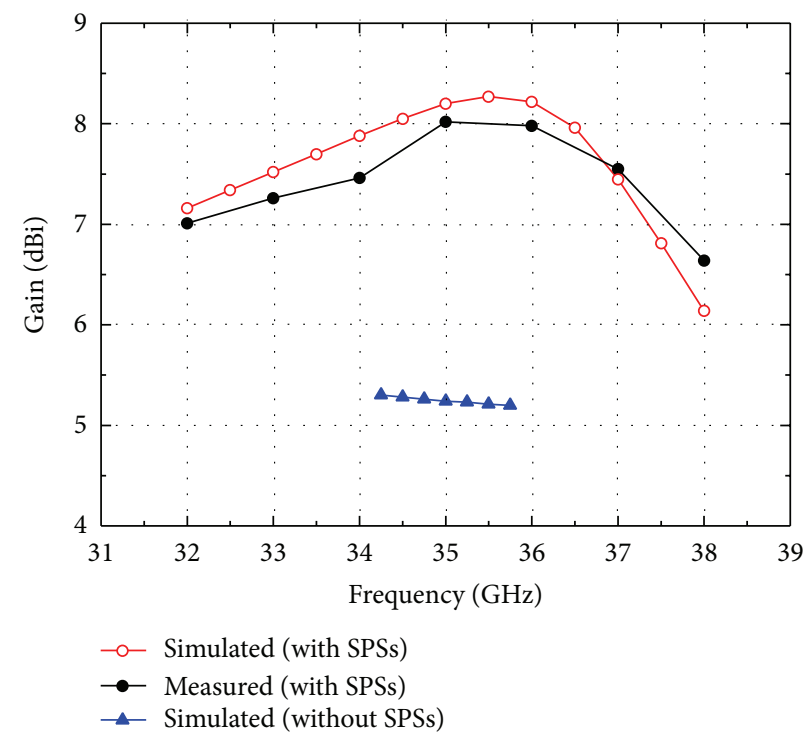

FIGURE 5: Simulated and measured gain of the LTCC patch antennas with and without SPSs.

as good radiation performance over its operating bandwidth. The results clearly demonstrate the effectiveness of utilizing SPSs to improve the bandwidth and gain of LTCC patch antennas. The proposed antenna may find applications in a number of radar and wireless communication systems.

\section{Conflict of Interests}

The authors declare that there is no conflict of interests regarding the publication of this paper.

\section{References}

[1] S. Brebels, J. Ryckaert, B. Côme et al., "SOP integration and codesign of antennas," IEEE Transactions on Advanced Packaging, vol. 27, no. 2, pp. 341-351, 2004.

[2] P. Pursula, T. Karttaavi, M. Kantanen et al., "60-GHz millimeterwave identification reader on 90-nm CMOS and LTCC," IEEE Transactions on Microwave Theory and Techniques, vol. 59, no. 4, pp. 1166-1173, 2011.

[3] A. Balankutty, S. Pellerano, T. Kamgaing, K. Tantwai, and Y. Palaskas, "A 12-element $60 \mathrm{GHz}$ CMOS phased array transmitter on LTCC package with integrated antennas," in Proceedings of the IEEE Asian Solid-State Circuits Conference (A-SSCC '11), pp. 273-276, Jeju, Republic of Korea, November 2011.

[4] A. Panther, A. Petosa, M. G. Stubbs, and K. Kautio, "A wideband array of stacked patch antennas using embedded air cavities in LTCC," IEEE Microwave and Wireless Components Letters, vol. 15, no. 12, pp. 916-918, 2005.

[5] K. L. Lau, S. H. Wong, and K. M. Luk, "Wideband folded feed L-slot folded patch antenna," IEEE Antennas and Wireless Propagation Letters, vol. 8, pp. 340-343, 2009.

[6] Z. Y. Zhang, G. Fu, S. L. Zuo, and S. X. Gong, "Wideband unidirectional patch antenna with $\Gamma$-shaped strip feed," Electronics Letters, vol. 46, no. 17, pp. 24-26, 2010.

[7] F. Yang, X. Zhang, X. Ye, and Y. Rahmat-Samii, "Wide-band E-shaped patch antennas for wireless communications," IEEE
Transactions on Antennas and Propagation, vol. 49, no. 7, pp. 1094-1100, 2001.

[8] S. H. Wi, Y. B. Sun, I. S. Song et al., "Package-level integrated antennas based on LTCC technology," IEEE Transactions on Antennas and Propagation, vol. 54, no. 8, pp. 2190-2197, 2006.

[9] A. E. I. Lamminen, A. R. Vimpari, and J. Säily, "UC-EBG on LTCC for $60-\mathrm{GHz}$ frequency band antenna applications," IEEE Transactions on Antennas and Propagation, vol. 57, no. 10, pp. 2904-2912, 2009.

[10] A. E. I. Lamminen, J. Säily, and A. R. Vimpari, "60-GHz patch antennas and arrays on LTCC with embedded-cavity substrates," IEEE Transactions on Antennas and Propagation, vol. 56, no. 9, pp. 2865-2874, 2008.

[11] T. Seki, N. Honma, K. Nishikawa, and K. Tsunekawa, "A 60$\mathrm{GHz}$ multilayer parasitic microstrip array antenna on LTCC substrate for system-on-package," IEEE Microwave and Wireless Components Letters, vol. 15, no. 5, pp. 339-341, 2005.

[12] C. A. Balanis, Antenna Theory: Analysis and Design, John Wiley \& Sons, New York, NY, USA, 3rd edition, 2005.

[13] D. M. Pozar, "A microstrip antenna aperture coupled to a microstrip Line," Electronics Letters, vol. 21, no. 2, pp. 49-50, 1985.

[14] S. Hudson and D. Pozar, "Grounded coplanar waveguide-fed aperture-coupled cavity-backed microstrip antenna," Electronics Letters, vol. 36, no. 12, pp. 1003-1005, 2000. 

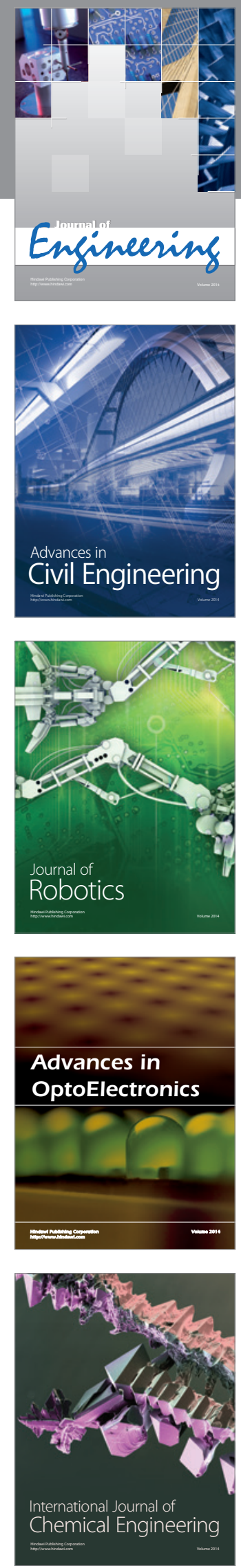

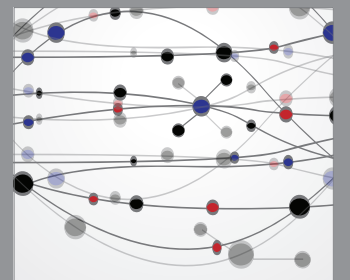

The Scientific World Journal


Submit your manuscripts at http://www.hindawi.com
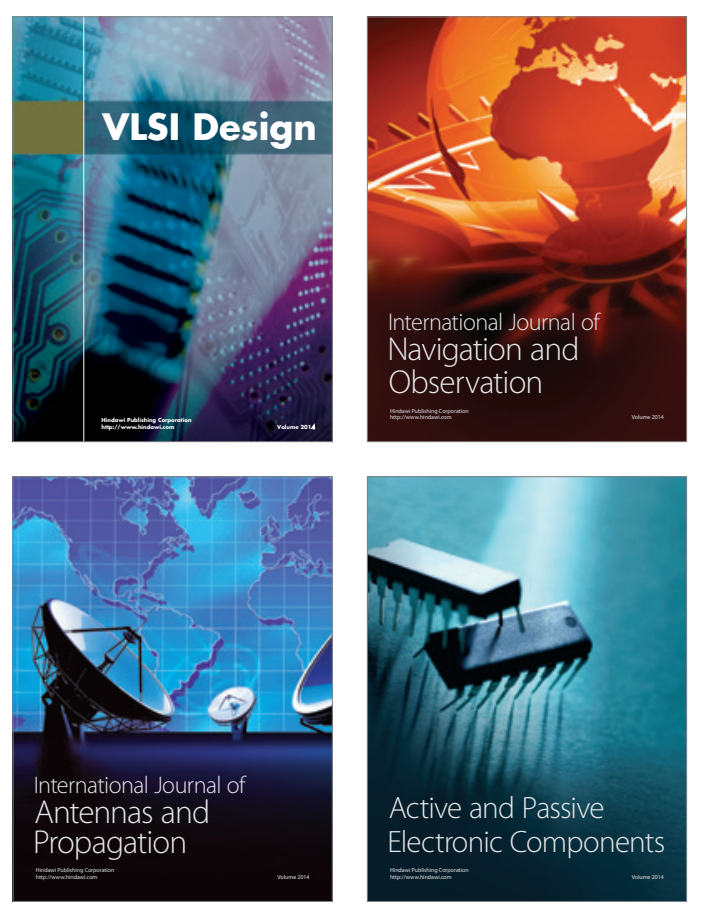
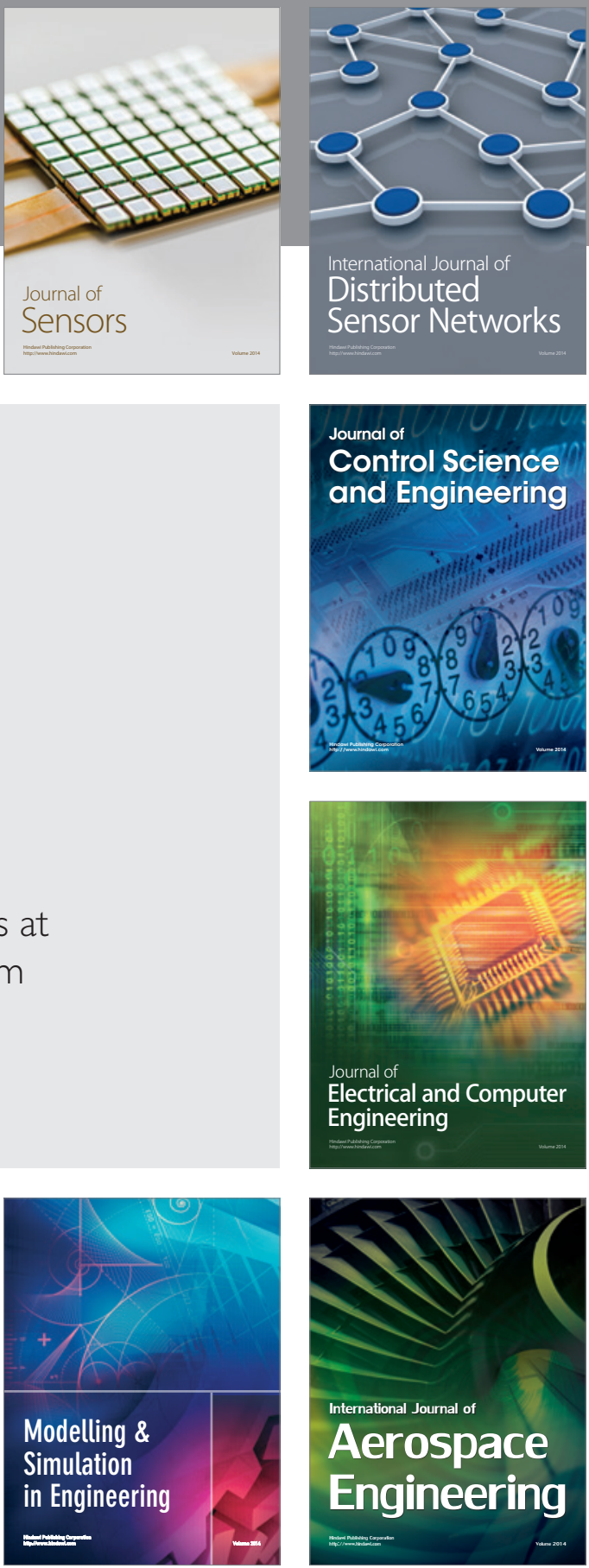

Journal of

Control Science

and Engineering
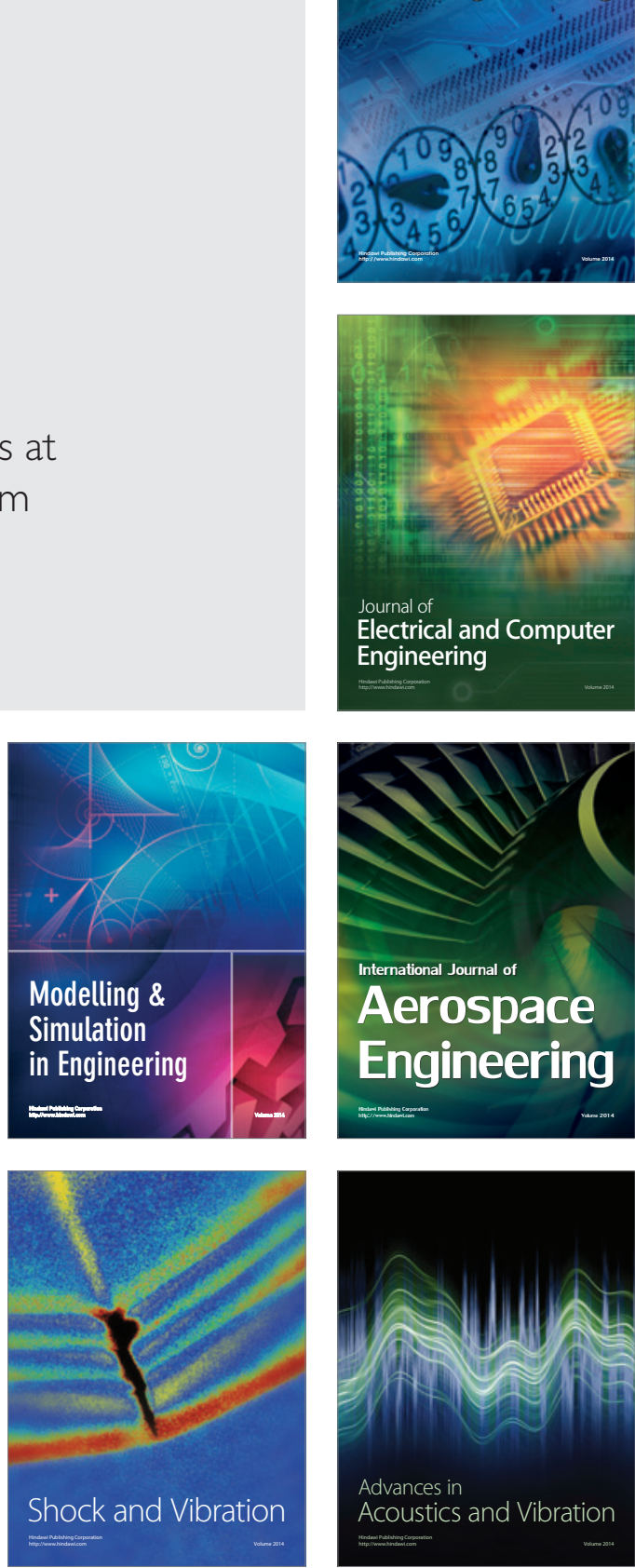